\title{
False Sero-Negative Results for Helicobacter pylori Infection Indicate Increased Risk of Severe Atrophic Gastritis in Japanese Patients
}

Hitomi Ichikawa $^{1}$, Mitsushige Sugimoto ${ }^{1}$, Mihoko Yamade ${ }^{1}$, Takahiro Uotani ${ }^{1}$, Shu Sahara ${ }^{1}$, Takuma Kagami ${ }^{1}$, Yasushi Hamaya $^{2}$, Moriya Iwaizumi ${ }^{1}$, Satoshi Osawa $^{3}$, Ken Sugimoto ${ }^{1}$, Hiroaki Miyajima ${ }^{1}$ and Takahisa Furuta ${ }^{4^{*}}$

${ }^{1}$ First Department of Medicine, Hamamatsu University School of Medicine, Hamamatsu, Japan

${ }^{2}$ Department of Clinical Oncology, Hamamatsu University School of Medicine, Hamamatsu, Japan

${ }^{3}$ Department of Endoscopic and Photodynamic Medicine, Hamamatsu University School of Medicine, Hamamatsu, Japan

${ }^{4}$ Center for Clinical Research, Hamamatsu University School of Medicine, Hamamatsu, Japan

*Corresponding author: Takahisa Furuta, MD, PhD, Center for Clinical Research, Hamamatsu University School of Medicine, 1-20-1, Handayama, Higashi-ku, Hamamatsu, 431-3192, Japan, Tel: 81-53-435-2850; Fax: 81-53-435-2851; E-mail:furuta@hama-med.ac.jp

Received date: Aug 13, 2014, Accepted date: Sep 18, 2014, Published date: Sep 23, 2014

Copyright: (C) 2014 Ichikawa $\mathrm{H}$, et al. This is an open-access article distributed under the terms of the Creative Commons Attribution License, which permits unrestricted use, distribution, and reproduction in any medium, provided the original author and source are credited.

\begin{abstract}
Background/objective: $H$. pylori infection is commonly diagnosed using an anti- $H$. pylori lgG antibody test. However, a proportion of results are falsely sero-negative. We investigated characteristics of patients falsely seronegative for $H$. pylori in relation to gastric atrophy.

Methods: $H$. pylori infection ( $\mathrm{Hp}+$ or $\mathrm{Hp}-$ ) was determined based on culture test, rapid urease test (RUT), and polymerase chain reaction (PCR) test in 280 outpatients. Anti-H. pylori antibody titers $\geq 10 \mathrm{U} / \mathrm{ml}$ were diagnosed as sero-positive for $H$. pylori (IgG+), while those $<10 \mathrm{U} / \mathrm{ml}$ were sero-negative (IgG-). Serum pepsinogen (PG) I/PG II ratios were calculated as a serological marker of gastric atrophy. Endoscopic gastric mucosal atrophy was also assessed according to the Kimura-Takemoto classification system.
\end{abstract}

Results: The mean PG I/PG II ratio in each group was as follows: Hp-/lgG- $(4.99 \pm 1.04, \mathrm{n}=10), \mathrm{Hp}+/ \mathrm{lgG}+(2.59 \pm$ 1.51, $n=240), \mathrm{Hp}-/ \operatorname{lgG}+(5.65 \pm 2.72, \mathrm{n}=4)$ and $\mathrm{Hp}+/ \operatorname{lgG}-(3.02 \pm 2.61, \mathrm{n}=26)$. The mean serum PG I/PG II ratio in the $\mathrm{Hp}+/ / \mathrm{lgG}$ - group was lower than those of $\mathrm{Hp}-/ \mathrm{lgG}-$ and $\mathrm{Hp}-/ \mathrm{lgG}+$ groups $(\mathrm{P}=0.028$ and 0.072$)$. Incidence of severe gastric mucosal atrophy in the $\mathrm{Hp}+/ / \mathrm{lgG}$ - group was highest of the four groups.

Conclusions: Individuals falsely sero-negative for $H$. pylori infection is at increased risk of severe atrophic gastritis, which is well known as precancerous lesion.

Keywords: Anti- $H$. pylori IgG antibody; Pepsinogen; Gastric atrophy

\section{Abbreviations:}

H. pylori: Helicobacter pylori; PG: Pepsinogen; IgG: Immunoglobulin G; RUT: Rapid Urease Test; UBT: Urea Breath test

\section{Introduction}

Chronic Helicobacter pylori (H. pylori) infection in gastric mucosa increases the risk of developing gastric cancer [1-5]. In particular, patients with $H$. pylori-associated severe atrophic gastric mucosa are at high risk of developing intestinal metaplasia, gastric adenoma, and gastric cancer [2]. Recently, the Japanese health insurance system permitted to check and eradicate $H$. pylori when the infection is present in patients with endoscopically proven gastritis [6]. Therefore, the accurate diagnosis of $H$. pylori infection is of clinical importance.

Several tests requiring endoscopy (i.e. culture, rapid urease test [RUT] and histology) and other tests without endoscopy (i.e. 13C-urea breath test [13C-UBT], stool antigen test and serological anti- $H$. pylori IgG antibody test) have been established for the detection of $H$. pylori infection in clinical practice [7]. The Maastricht IV/Florence Consensus Report recommends the 13C-UBT and stool antigen test to detect H. pylori infection, due to high sensitivity and specificity [7]. However, the anti- $H$. pylori IgG antibody test is typically used to check infection, particularly in health check-ups in Japan, because it is simple and inexpensive [8]. As sensitivity and specificity of the anti-H.pylori IgG antibody test is approximately $90 \%-95 \%[7,9]$, some $5 \%-10 \%$ of those assessed are falsely diagnosed by this test. If patients are misdiagnosed as uninfected with $H$. pylori, they will not undergo gastroscopy, which increases the risk of oversight of gastric cancer and other $H$. pylori related disorders. Therefore, elucidation of the clinical characteristics of individuals that are falsely negative for anti- $H$. pylori IgG antibody is of clinical importance.

Pepsinogen (PG) I and PG II, the two main precursors of pepsin, are both produced by chief cells and mucous neck cells of the stomach $[10,11]$. PG II is also produced by pyloric gland cells. Approximately $1 \%$ of PG I and PG II reach the systemic circulation, which can be detected and measured in the serum. Gastric inflammation increases the proportion of PG I and PG II that reach the blood stream. As gastric atrophy progresses, chief cells in the gastric corpus decrease and are replaced with pyloric glands, leading to a decrease in serum PG I levels. Therefore, both a low serum PG I and low PG I/PG II ratio are recognized as serological markers of gastric atrophy [12-14]. In Japan, serum PG I level $\leq 70 \mathrm{ng} / \mathrm{ml}$ and PG I/PG II ratio $\leq 3.0$ indicate 
severe gastric mucosal atrophy, which is called as "positive for the PG method" [14].

Recently, a combination of serum PG and anti- $H$. pylori IgG antibody tests, called the $\mathrm{ABC}$ classification, has been used to evaluate an individual risk for gastric cancer $[2,15,16]$. In the $A B C$ classification, the risk of gastric cancer is classified into four groups as follows; Subjects classified into the group A are both negative for antiH. pylori IgG antibody and the PG method. Those classified into the group $\mathrm{B}$ are positive for anti-H. pylori IgG antibody but negative for the PG method. Those classified into the group $\mathrm{C}$ are positive for both anti-H. pylori IgG antibody and the PG method. Those classified into group $\mathrm{D}$ are negative for anti- $H$. pylori IgG antibody but positive for PG method. Interestingly, individuals in Group D of this classification (serum PG I level $\leq 70 \mathrm{ng} / \mathrm{ml}$, PG I/PG II ratio $\leq 3.0$ and negative for anti- $H$. pylori IgG antibody) are known to be at the highest risk of developing gastric cancer. Although the sensitivity of this classification was reported as $70.5 \%$ and specificity as $97.0 \%$ [17], a considerable problem remains in that a certain proportion of patients in Group A (serum PG I level $>70 \mathrm{ng} / \mathrm{ml}$ or PG I/PG II ratio $>3.0$, and negative for anti- $H$. pylori $\operatorname{IgG}$ antibody) and $\mathrm{D}$ are false negative in the $\operatorname{IgG}$ serology test.

Here, we investigated the characteristics of patients who were falsely sero-negative for $H$. pylori in relation to serum PG levels and endoscopic gastric mucosal atrophy.

\section{Patients and Methods}

\section{Patients:}

A total of 280 outpatients who underwent gastroscopy for screening of $H$. pylori infection at the University Hospital of Hamamatsu University School of Medicine were enrolled. Mean age was $58.0 \pm$ 11.8 years. The cohort consisted of 170 males $(60.7 \%)$ and 110 females (39.3\%). They consisted of patients with hyperplastic polyp $(n=8)$, gastric cancer $(n=6)$, MALT lymphoma $(n=4)$, gastritis alone $(n=227)$, or either or both gastric or duodenal ulcer $(n=32)$ and functional dyspepsia $(n=3)$.

\section{Serum levels of anti- $\boldsymbol{H}$. pylori antibody titer and PGs:}

We obtained sera from all subjects. Serum anti- $H$. pylori IgG antibody was determined using a commercial kit (E-plate Eiken; Eiken Chemical Co., Ltd., Tochigi, Japan). Samples with an anti- $H$. pylori IgG titer $<10 \mathrm{U} / \mathrm{ml}$ were diagnosed as sero-negative for $H$. pylori, defined as "IgG-". Samples with an anti- $H$. pylori IgG titer $\geq$ $10 \mathrm{U} / \mathrm{ml}$ were diagnosed as sero-positive for $H$. pylori, defined as "IgG + " in accordance with the manufacture's protocol [18]. Serum levels of PG I and II were measured using a commercial kit (Pepsinogen CLEIA*; Fuji Rebio., Ltd., Tokyo, Japan). PG I/PG II ratios were calculated as a serological marker of gastric atrophy. PG I/PG II ratio $\leq$ 3.0 indicated severe gastric atrophy and an increased risk of gastric cancer[14].

\section{Gastroduodenoscopy and diagnosis of $\boldsymbol{H}$. pylori infection:}

Endoscopists were unaware of clinical information of each patient, such as serum PG I, PG II and anti-H. pylori antibody.

During gastroduodenoscopy, immediately after entering the stomach, $5 \mathrm{ml}$ of gastric juice was aspirated through the suction channel of the endoscope and collected in a trap placed in the suction line [19]. Routine inspection of the upper gastrointestinal tract was performed, and several biopsy specimens from both the antrum and the corpus were then obtained for RUT and bacteriological culture as described below.

Endoscopic gastric mucosal atrophy was assessed according to the Kimura-Takemoto classification system and classified into three groups as follows: none/mild, C-0 - C-II; moderate, C-III - O-I; and severe, O-II - O-III [20]. For the RUT, biopsy specimens were inoculated into a commercial kit (Helicocheck ${ }^{\oplus}$ Otsuka Pharmaceutical Co, Ltd., Tokyo, Japan), and any color change was noted after $30 \mathrm{~min}$ and $2 \mathrm{~h}$. A color change from yellow to pink within $2 \mathrm{~h}$ was judge as a positive result [21].

For the bacterial culture test, biopsy specimens were inoculated onto agar plates (E-MR82; Eiken Chemical Co, Ltd., Tochigi, Japan) and incubated at $37^{\circ} \mathrm{C}$ under microaerophilic conditions for up to 7 days [19]. Colonies were identified as $H$. pylori based on morphology in Gram stains, oxidase test, and RUT [19].

For PCR analysis, DNA was extracted from gastric juice samples by the boiling method and subjected to PCR analysis of $H$. pylori infection using the automated gene analyzer, GENECUBE ${ }^{\bullet}$ (Toyobo Co., Ltd., Fukui, Japan) as previously described [22].

When any one of the three detection tests (PCR, culture or RUT) were positive, subjects were diagnosed with $H$. pylori infection and defined as "Hp+". When all tests were negative, subjects were diagnosed as uninfected with $H$. pylori and defined as "Hp-".

Subjects uninfected with $H$. pylori and negative for anti- $H$. pylori IgG antibody were classified as $\mathrm{Hp}$-/IgG-, those infected with $H$. pylori and positive for anti- $H$. pylori IgG antibody were classified as $\mathrm{Hp}+/ \mathrm{IgG}+$, those infected with $H$. pylori but negative for anti- $H$. pylori IgG antibody were classified as $\mathrm{Hp}+/ \mathrm{IgG}-$, and those uninfected with $H$. pylori but positive for anti- $H$. pylori IgG antibody were classified as Hp-/IgG+.

The protocol was approved in advance by the Human Institutional Review Board of Hamamatsu University School of Medicine, and a written informed consent was obtained from each subject.

\section{Statistics:}

All numerical values are expressed as means \pm standard deviations (SD). Statistical differences in serum PG values among subgroups were assessed via one-way ANOVA (analysis of variance) with Scheffe's multiple comparison test. Whether or not incidences of different grades of endoscopic gastric mucosal atrophy differed among subgroups was assessed via the chi-square test. All P-values were twosided. $\mathrm{P}<0.05$ was considered as statistically significant. Calculations were carried out using StatView 5.0 statistical software (SAS Institute, Cary, NC, USA).

\section{Results}

A total of 280 subjects were enrolled in the study. Mean serum level of PG I was $58.0 \pm 36.9 \mathrm{ng} / \mathrm{ml}$, and that of PG II was $24.0 \pm 15.2 \mathrm{ng} / \mathrm{ml}$. Mean PG I/PG II ratio was $3.0 \pm 1.7$, and mean anti- $H$. pylori IgG titer was $49.0 \pm 39.8 \mathrm{U} / \mathrm{ml}$. Two hundred and forty-four (87.1\%) subjects tested positive in the anti- $H$. pylori IgG antibody test, $251(89.3 \%)$ in the RUT, 258 (92.1\%) in the PCR test, and 194 (69.3\%) in the culture test (Table 1). A total of 266 subjects had positive result with any of the three tests (i.e., RUT, PCR and culture test) and were diagnosed to be 
Citation: Ichikawa H, Sugimoto M, Yamade M, Uotani T, Sahara S, et al. (2014) False Sero-Negative Results for Helicobacter pylori Infection Indicate Increased Risk of Severe Atrophic Gastritis in Japanese Patients. J Carcinog Mutagen 5: 192. doi:10.4172/2157-2518.1000192

Page 3 of 7

infected with $H$. pylori $(\mathrm{Hp}+)$. Remaining 14 were diagnosed to be uninfected with $H$. pylori (Hp-).

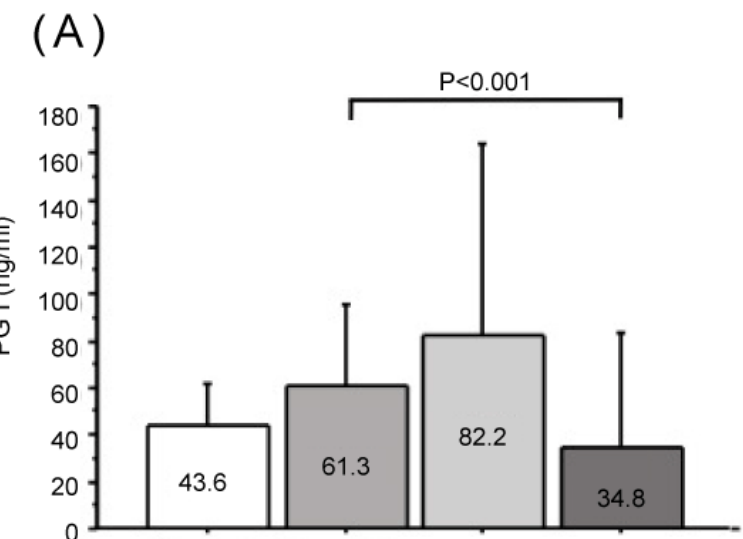

$\mathrm{Hp}-/ / \mathrm{gG}-\mathrm{Hp}+/ \mathrm{lgG}+\mathrm{Hp}-/ \mathrm{lgG}+\mathrm{Hp}+/ \mathrm{lgG}-$

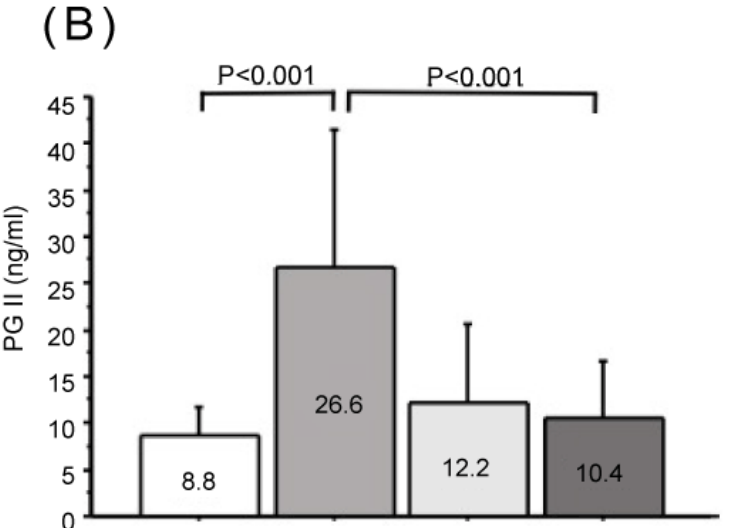

$\mathrm{Hp}-/ \mathrm{lgG}-\mathrm{Hp}+/ \mathrm{lgG}+\mathrm{Hp}-/ \mathrm{lgG}+\mathrm{Hp}+/ \mathrm{lgG}-$

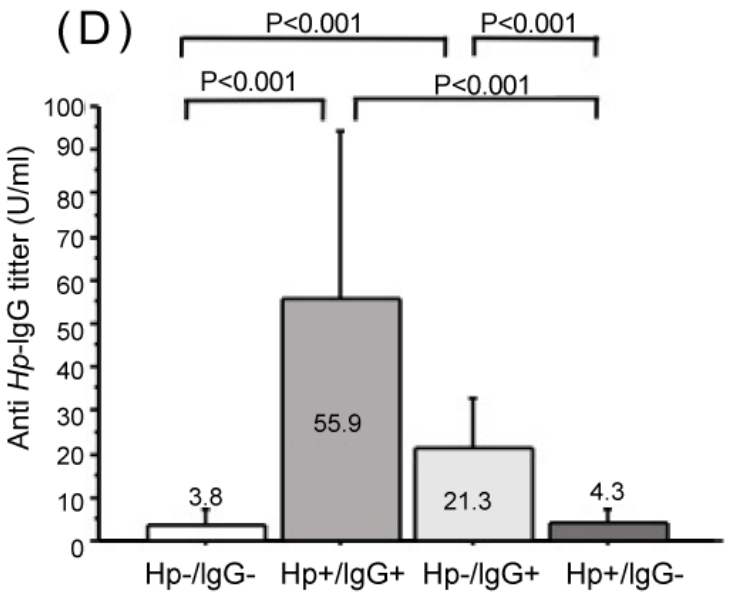

Figure 1: Mean serum PG I (A), PG II (B), PG I/PG II ratios (C) and anti- H. pylori IgG antibody titer (D) in Hp-/IgG-, HP+/IgG+, Hp-/IgG+ and $\mathrm{Hp}+/ \mathrm{IgG}-$ groups. Bars indicate standard deviations. Abbreviations are: Hp-/IgG-, uninfected with $H$. pylori and negative for anti- $H$. pylori IgG antibody; $\mathrm{Hp}+/ \mathrm{IgG}+$, infected with $H$. pylori and positive for anti- $H$. pylori IgG antibody; Hp-/IgG+, uninfected with $H$. pylori but positive for anti- $H$. pylori IgG antibody; $\mathrm{Hp}+/ \mathrm{IgG}-$, infected with $H$. pylori but negative for anti- $H$. pylori IgG antibody.

Clinical demographic characteristics of four groups, Hp-/IgG-, Hp $+/$ IgG+, Hp-/IgG+ and Hp+/IgG-, were summarized in Table 2. Ten (3.6\%) subjects were classified as $\mathrm{Hp}-/ \mathrm{IgG}-, 240$ (85.7\%) as $\mathrm{Hp}+/ \mathrm{IgG}+$, $4(1.4 \%)$ as $\mathrm{Hp}-/ \mathrm{IgG}+$, and $26(9.3 \%)$ as $\mathrm{Hp}+/ \mathrm{IgG}-$. The mean age of the $\mathrm{Hp}+/ \mathrm{IgG}$ - group was $66.1 \pm 13.8$, which was slightly higher in comparison with other three groups. There were no significant differences in male/female ratios among the four groups (Table 2).

\begin{tabular}{|l|l|}
\hline Characteristic & Value \\
\hline Male/Female (\% ratio) & $170 / 110(60.7 \% / 39.3 \%)$ \\
\hline Age (years) & $58.0 \pm 11.7$ \\
\hline PG I (ng/ml) & $58.0 \pm 36.9$ \\
\hline PG II (ng/ml) & $24.0 \pm 15.2$ \\
\hline
\end{tabular}

\begin{tabular}{|l|l|}
\hline PG I/ PG II ratio & $3.0 \pm 1.7$ \\
\hline Anti H. pylori-IgG titer (U/ml) & $49.0 \pm 39.8$ \\
\hline Anti H. pylori-IgG (positive) & $244(87.1 \%)$ \\
\hline Eradication history (none) & $190(67.8 \%)$ \\
\hline RUT (positive) & $250(89.3 \%)$ \\
\hline PCR (positive) & $254(90.7 \%)$ \\
\hline Culture (positive) & $195(69.6 \%)$ \\
\hline
\end{tabular}

Table 1: Patient characteristics. Values are presented as mean \pm standard deviation PG I, pepsinogen I; PG II, pepsinogen II; RUT, rapid urease test 
Citation: Ichikawa H, Sugimoto M, Yamade M, Uotani T, Sahara S, et al. (2014) False Sero-Negative Results for Helicobacter pylori Infection Indicate Increased Risk of Severe Atrophic Gastritis in Japanese Patients. J Carcinog Mutagen 5: 192. doi:10.4172/2157-2518.1000192

Page 4 of 7

Mean serum PG I level of each group was demonstrated in Figure 1A. Mean serum PG I level of the Hp+/IgG- group was significantly lower than that of the $\mathrm{Hp}+/ \mathrm{IgG}+$ group $(\mathrm{P}<0.001)$, but not that of the Hp-/IgG- or Hp+/IgG- group. Mean serum PG II level of each group was demonstrated in Figure 1B. Mean serum PG II level of the Hp+l IgG- group was significantly lower than that of the $\mathrm{Hp}+/ \mathrm{IgG}+$ group $(\mathrm{P}<0.001)$. Mean of serum PG I/PG II ratio of each group was demonstrated in Figure 1C. Mean of serum PG I/PG II ratio in the Hp $+/$ IgG- group was lower than that in the Hp-/IgG- or Hp-/IgG+ group $(\mathrm{P}=0.028$ and 0.072$)$. Mean anti-H. pylori IgG titer of each group was demonstrated in Figure 1D. In the IgG- groups, the mean titer of antiH. pylori IgG antibody in $\mathrm{Hp}+/ \mathrm{IgG}$ - or $\mathrm{Hp}$-/IgG- groups were no 0 , indicating that patients with low titers for anti-H. pylori IgG antibody were included in the $\mathrm{Hp}+/ \mathrm{IgG}$ - or Hp-/IgG- groups.

\begin{tabular}{|c|c|c|c|c|c|}
\hline & $\mathrm{HP}-/ \operatorname{lgG}-\mathrm{N}=10(3.6 \%)$ & $\mathrm{HP}+/ \mathrm{lgG}+\mathrm{N}=240(85.7 \%)$ & $\begin{array}{l}\mathrm{HP}-/ / \mathrm{gG}+ \\
\mathrm{N}=4(1.4 \%)\end{array}$ & HP+/lgG- N=26 (9.3\%) & P-value \\
\hline Male/Female & $8 / 2(80.0 \% / 20.0 \%)$ & $141 / 99(58.8 \% / 41.2 \%)$ & $3 / 1(75.0 \% / 25.0 \%)$ & $18 / 8(69.2 \% / 30.8 \%)$ & 0.379 \\
\hline Age (years) & $63.4 \pm 8.6$ & $56.5 \pm 11.0$ & $63.3 \pm 16.6$ & $66.1 \pm 13.8$ & $<0.001$ \\
\hline Eradication history (none) & $5(50.0 \%)$ & $178(74.2 \%)$ & $1(25.0 \%)$ & $6(23.1 \%)$ & 0.383 \\
\hline RUT (positive) & 0 & $234(97.5 \%)$ & 0 & $16(64.0 \%)$ & $<0.001$ \\
\hline PCR (positive) & 0 & $230(95.8 \%)$ & 0 & $24(92.3 \%)$ & $<0.001$ \\
\hline Culture (positive) & 0 & $193(80.4 \%)$ & 0 & $2(7.7 \%)$ & $<0.001$ \\
\hline $\begin{array}{l}\text { ABC classification } \\
\text { A/B/C/D }(n / n / n / n)\end{array}$ & $10 / 0 / 0 / 0$ & $0 / 113 / 127 / 0$ & $0 / 3 / 1 / 0$ & $11 / 0 / 0 / 15$ & $<0.001$ \\
\hline
\end{tabular}

Table 2: Demographic clinical characteristics of each group. Values are presented as mean \pm standard deviation Hp-/IgG-, uninfected with $H$. pylori and negative for anti-H. pylori IgG antibody; $\mathrm{Hp}+/ \mathrm{IgG}+$, infected with $H$. pylori and positive for anti-H. pylori IgG antibody; Hp-/IgG+, uninfected with $H$. pylori but positive for anti-H. pylori IgG antibody; Hp+/IgG-, infected with $H$. pylori but negative for anti-H. pylori IgG antibody.

\section{( A )}

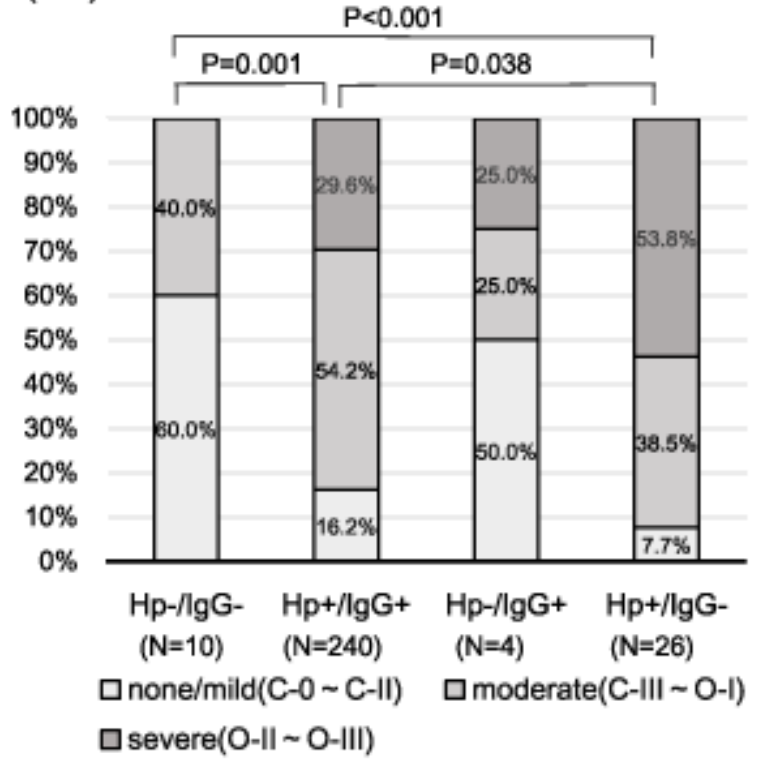

( B )

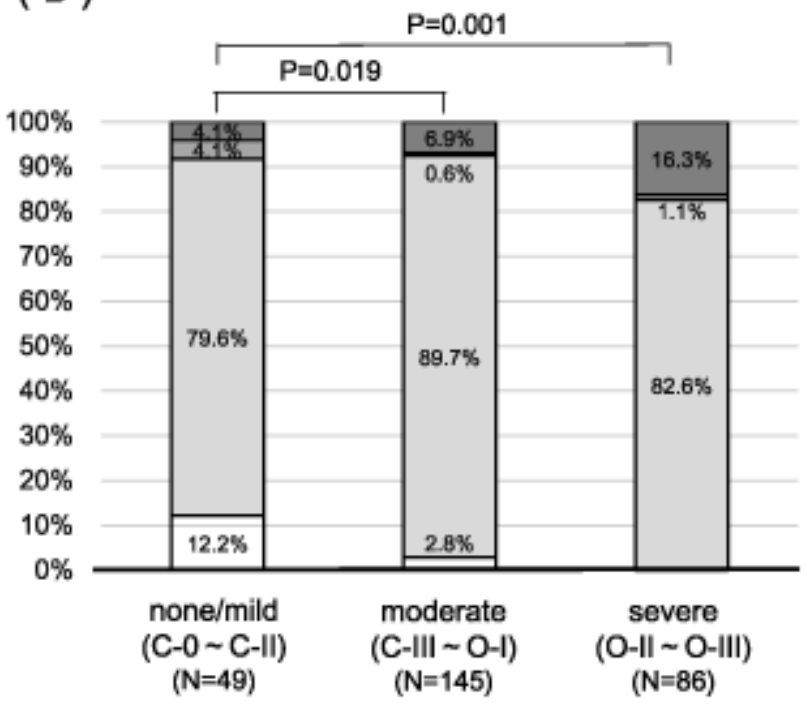

口Hp-/lgG- $\square \mathrm{Hp}+/ / \mathrm{lgG}+\square \mathrm{Hp}-/ / \mathrm{gG}+\square \mathrm{Hp}+/ \mathrm{lgG}-$

Figure 2: Incidence of endoscopic gastric mucosal atrophy in Hp-/IgG-, HP+/IgG+, Hp-/IgG+ and Hp+/IgG- groups (A) and the percentage of four groups (Hp-/IgG-, $\mathrm{HP}+/ \mathrm{IgG}+, \mathrm{Hp}-/ \mathrm{IgG}+$ and $\mathrm{Hp}+/ \mathrm{IgG}-$ ) in different gastric mucosal atrophy grade (B). Abbreviations same as Figure 1 .

Incidences of different grades of endoscopic gastric mucosal atrophy in the four groups are summarized in Figure 2. Incidence of moderate (C-III - O-I) and severe gastric mucosal atrophy (O-II - O-
III), particularly severe atrophy, was highest in the $\mathrm{Hp}+/ \mathrm{IgG}$ - group (Figure 2A). The incidence of falsely sero-negative subjects $(\mathrm{Hp}+/$ IgG-) became higher as the grades of atrophic gastritis progressed 
Citation: Ichikawa H, Sugimoto M, Yamade M, Uotani T, Sahara S, et al. (2014) False Sero-Negative Results for Helicobacter pylori Infection Indicate Increased Risk of Severe Atrophic Gastritis in Japanese Patients. J Carcinog Mutagen 5: 192. doi:10.4172/2157-2518.1000192

Page 5 of 7

from non/mild (C-0 - C-II) to moderate (C-II - O-I) and severe (O-II -

O-III) (Figure 2B).

\begin{tabular}{|c|c|c|c|c|c|c|c|}
\hline Sex & Age (years) & Anti-H. pylori lgG titer (U/ml) & $A B C$ method & $\begin{array}{l}\text { Endoscopic gastric mucosal } \\
\text { atrophy }\end{array}$ & RUT & Culture & PCR \\
\hline M & 75 & $<3$ & $\mathrm{D}$ & O-II & $P$ & $\mathrm{~N}$ & $P$ \\
\hline $\mathrm{F}$ & 64 & $<3$ & D & C-II & ND & $\mathrm{N}$ & $P$ \\
\hline $\mathrm{F}$ & 66 & $<3$ & D & O-III & $P$ & $\mathrm{~N}$ & $P$ \\
\hline $\mathrm{F}$ & 74 & $<3$ & D & O-III & $P$ & $\mathrm{~N}$ & $P$ \\
\hline M & 72 & 3 & D & O-III & $P$ & $\mathrm{~N}$ & $P$ \\
\hline M & 74 & 4 & D & O-III & $P$ & $\mathrm{~N}$ & $P$ \\
\hline M & 75 & 4 & $\mathrm{D}$ & O-III & N & $\mathrm{N}$ & $P$ \\
\hline M & 81 & 4 & D & O-III & N & $\mathrm{N}$ & $P$ \\
\hline M & 81 & 4 & D & O-III & $\mathrm{N}$ & $\mathrm{N}$ & $P$ \\
\hline M & 74 & 5 & $\mathrm{D}$ & O-III & $\mathrm{P}$ & N & $\mathrm{P}$ \\
\hline $\mathrm{F}$ & 67 & 5 & D & O-III & $\mathrm{N}$ & $\mathrm{N}$ & $P$ \\
\hline M & 70 & 6 & D & O-III & $P$ & $P$ & $P$ \\
\hline M & 67 & 8 & D & O-I & $P$ & $\mathrm{~N}$ & $P$ \\
\hline M & 62 & 9 & D & O-I & $\mathrm{N}$ & $\mathrm{N}$ & $P$ \\
\hline M & 74 & 9 & D & O-III & $\mathrm{N}$ & $\mathrm{N}$ & $P$ \\
\hline M & 41 & $<3$ & A & C-III & $P$ & $\mathrm{~N}$ & $P$ \\
\hline M & 54 & $<3$ & A & O-I & $\mathrm{N}$ & $\mathrm{N}$ & $P$ \\
\hline M & 70 & $<3$ & A & O-III & $P$ & $\mathrm{~N}$ & $P$ \\
\hline M & 87 & 3 & A & O-I & $P$ & $\mathrm{~N}$ & $\mathrm{~N}$ \\
\hline M & 76 & 4 & A & O-I & $P$ & $\mathrm{~N}$ & $P$ \\
\hline $\mathrm{F}$ & 41 & 5 & A & O-I & $\mathrm{N}$ & $\mathrm{N}$ & $P$ \\
\hline $\mathrm{F}$ & 62 & 7 & A & C-III & $P$ & $\mathrm{~N}$ & $P$ \\
\hline $\mathrm{F}$ & 66 & 7 & A & O-I & $P$ & $\mathrm{~N}$ & $P$ \\
\hline M & 48 & 8 & A & C-III & $P$ & $P$ & $P$ \\
\hline M & 71 & 8 & A & O-II & $P$ & $\mathrm{~N}$ & $\mathrm{~N}$ \\
\hline $\mathrm{F}$ & 27 & 9 & A & C-II & $\mathrm{N}$ & $\mathrm{N}$ & $P$ \\
\hline
\end{tabular}

Table 3: Clinical characteristics of the Hp+/IgG- group. Hp+/IgG-, infected with $H$. pylori but negative for anti- $H$. pylori IgG antibody; RUT, rapid urease test; $M$, male; $F$, female; $P$, positive; $N$, negative; $N D$, no data.

Although only 2 of the 26 subjects of the Hp+/IgG- group were positive for the culture test, $16(64.0 \%)$ were positive for RUT, and 24 (92.3\%) were positive for PCR (Table 3). Based on the ABC classification, 15 of the $\mathrm{Hp}+/ \mathrm{IgG}$ - group belonged to Group D, while the remaining 11 patients belonged to Group A. Moreover, the antiH.pylori IgG antibody titer $<3$ were observed in only 7 of $26(26.9 \%)$ patients. Remaining 19 patients $(73.1 \%)$ had the low titer $(3-9 \mathrm{U} / \mathrm{ml})$ of the anti- $H$. pylori IgG antibody.

\section{Discussion}

In the present study, we found that $9.3 \%$ of patients enrolled in this study were falsely sero-negative for $H$. pylori infection. This result was consistent with a previous report [23]. We also observed that mean age of $\mathrm{Hp}+/ \mathrm{IgG}$ - group was slightly higher than that of other groups, that the mean of serum PG I/PG II ratio in the $\mathrm{Hp}+/ \mathrm{IgG}$ - group was lower than that of in the $H$. pylori-negative groups and that endoscopic gastric mucosal atrophy of the $\mathrm{Hp}+/ \mathrm{IgG}-$ group was the most advanced of the four groups. Patients who were judged falsely sero- 
negative (Hp+/IgG- group) were therefore considered to be at a high risk of developing gastric cancer.

The problems of falsely sero-negative for $H$. pylori have been reported previously. Ootani, et al. [24] reported that $9.5 \%$ of $H$. pylori sero-negative subjects had endoscopically atrophic gastritis. Yamaji et al. [25] reported that weakly positive for anti- H. pylori IgG antibody is a major risk factor for gastric cancer, particularly in the elderly. Given that a proportion of patients in the falsely sero-negative group had a low titer of anti- $H$. pylori antibody (e.g. 3-9 U/ml), they were considered the same as the weakly positive group. Some reports have noted that patients with gastric cancer had low titers of anti- $H$. pylori IgG antibody [26-29] and suggested that the weakly positive group might have diminished immune function and be unable to adequately respond to $H$. pylori antigen. Chen et al. [30] reported that degradation of the immune response to $H$. pylori might increase the risk of gastric cancer. Together, these findings suggest that changes in systemic and local immune response to $H$. pylori might be associated with sero-negativity and carcinogenesis in the stomach [31,32]. Further studies are needed to clarify the causative relationship between development of gastric cancer and low titers of anti- $H$. pylori IgG antibody.

The characteristics of Group D under ABC classification appear similar to those of the Hp+/IgG- group in the present study. Individuals classified into Group D are considered to have cleared infection naturally by severe gastric mucosal atrophy [33]. However, the results of our present study demonstrated that more than half of the patients in the Hp+/IgG- group were classified into Group D. Therefore, the considerable proportion of individuals in Group D may actually be infected with $H$. pylori. In fact, all patients classified as Group D in the present study were deemed to be infected with $H$. pylori based on either culture, RUT or PCR or both findings. Diminished immune response to $H$. pylori is also suggested to occur in Group D [31,32].

The remaining 11 subjects in the $\mathrm{Hp}+/ \mathrm{IgG}$ - group were classified into Group A under the ABC classification system. Members of Group A are considered to have no $H$. pylori infection and be at low risk of gastric cancer and healthy gastric mucosa $[1,34,35]$; however, our study results demonstrated that some members of Group A may indeed be $H$. pylori-positive. All of the 11 individuals had atrophic gastritis from Grade C-II to O-III (Table 3). Therefore, diagnosis of $H$. pylori infection based on serum anti- $H$. pylori IgG antibody alone appears to be insufficient and risks oversight of severe atrophic gastritis. Endoscopy and other diagnostic tests for $H$. pylori infection are therefore necessary for more accurate diagnosis of $H$. pylori infection, even in Group A. Further, reassessment of the cut off level of the antibody titer is also required. In patients falsely sero-negative, the PCR method was able to detect $H$. pylori infection at $92.3 \%(n=24)$ and RUT at $64.0 \%(\mathrm{n}=16)$. Combined detection might therefore diagnose $H$. pylori infection more accurately than using single method.

In this study, four subjects in the Hp-/IgG+ group were considered falsely sero-positive. Three of the four subjects had a history of eradication of $H$. pylori infection, suggesting the process that antibody titer was decreasing in the subjects after eradication who were misdiagnosed as having unsuccessful eradication. We therefore consider an interview concerning eradication history to be important when diagnosing $H$. pylori.
Several limitations to the present study warrant mention. First, this study had a small sample size and was a single center study. Second, $H$. pylori infection was detected via a culture test, RUT, and PCR test. For more accurate diagnosis, we should have conducted tests with higher sensitivity and specificity, such as the 13C-UBT or stool antigen test [7]. Third, as the population in this study included many H. pyloriinfected subjects, there was a degree of bias in the results. We consider a similar study in the general population to be necessary. Therefore, the results of the present study should be considered with care and a multicenter study with large sample size performed to clarify the characteristics of falsely sero-negative subjects.

In conclusion, the results of the present study suggest that individuals who are falsely sero-negative for $H$. pylori infection have a high risk of severe atrophic gastritis, which is known as a precancerous lesion. Although the serological test for $H$. pylori is a simple and easy assay for screening $H$. pylori infection, it carries a risk of false-negative results. Combined detection, such as 13C-UBT, RUT, stool antigen test, culture test and/or histology, might therefore provide a more accurate diagnosis of $H$. pylori infection when serological test is negative. Then, we would like to offer the following recommendation; Patients with the anti-H. pylori IgG antibody $\geq 10 \mathrm{U} / \mathrm{ml}$ can be considered as $H$. pylori positive. Patients whose anti- $H$. pylori IgG antibody are 3-9 $\mathrm{U} / \mathrm{ml}$ are suspicious for $H$. pylori infection and should undergo the alternative examination for $H$. pylori infection. Patients whose anti- $H$. pylori IgG antibody are $<3 \mathrm{U} / \mathrm{ml}$ could be considered as $H$. pylori-negative, but should be recommend to have another examination if they are elderly. However, validity of our recommendation must be verified in the future prospective study.

\section{Acknowledgements}

The assistance of the endoscopy staffs is greatly appreciated. This study was partly supported by Grants-in-Aid for Scientific Research from the Ministry of Education, Culture, Science, and Sports of Japan (23590913).

\section{Conflict of interest:}

This study was partly supported by Grants-in-Aid for Scientific Research from the Ministry of Education, Culture, Science, and Sports of Japan (23590913). The Center for Clinical Research and the First Department of Medicine at Hamamatsu University School of Medicine have received grants from Takeda Pharmaceutical Co., Ltd.; AstraZeneca KK, Eisai Co., Ltd.; Daiichi-Sankyo Co. Ltd.; and Drs. Furuta and Sugimoto have received lecture fees from those companies. The authors have no other conflicts of interest that are directly relevant to the content of this article.

\section{References:}

1. Uemura N, Okamoto S, Yamamoto S, Matsumura N, Yamaguchi S, et al. (2001) Helicobacter pylori infection and the development of gastric cancer. N Engl J Med 345: 784-789.

2. Ohata H, Kitauchi S, Yoshimura N, Mugitani K, Iwane M, et al. (2004) Progression of chronic atrophic gastritis associated with Helicobacter pylori infection increases risk of gastric cancer. Int J Cancer 109: 138-143.

3. Forman D, Newell DG, Fullerton F, Yarnell JW, Stacey AR, et al. (1991) Association between infection with Helicobacter pylori and risk of gastric cancer: evidence from a prospective investigation. BMJ 302: 1302-1305.

4. Parsonnet J, Friedman GD, Vandersteen DP, Chang Y, Vogelman JH, et al. (1991) Helicobacter pylori infection and the risk of gastric carcinoma. N Engl J Med 325: 1127-1131. 
5. Take S, Mizuno M, Ishiki K, Nagahara Y, Yoshida T, et al. (2005) The effect of eradicating helicobacter pylori on the development of gastric cancer in patients with peptic ulcer disease. Am J Gastroenterol 100: 1037-1042.

6. Asaka M (2013) A new approach for elimination of gastric cancer deaths in Japan. Int J Cancer 132: 1272-1276.

7. Malfertheiner P, Megraud F, O'Morain CA, Atherton J, Axon AT, et al. (2012) Management of Helicobacter pylori infection--the Maastricht IV/ Florence Consensus Report. Gut 61: 646-664.

8. Asaka M, Kato M, Takahashi S, Fukuda Y, Sugiyama T, et al. (2010) Guidelines for the management of Helicobacter pylori infection in Japan: 2009 revised edition. Helicobacter 15: 1-20.

9. Burucoa C, Delchier JC, Courillon-Mallet A, de Korwin JD, Mégraud F, et al. (2013) Comparative evaluation of 29 commercial Helicobacter pylori serological kits. Helicobacter 18: 169-179.

10. Samloff IM (1971) Cellular localization of group I pepsinogens in human gastric mucosa by immunofluorescence. Gastroenterology 61: 185-188.

11. Samloff IM, Liebman WM (1973) Cellular localization of the group II pepsinogens in human stomach and duodenum by immunofluorescence. Gastroenterology 65: 36-42.

12. Samloff IM, Varis K, Ihamaki T, Siurala M, Rotter JI (1982) Relationships among serum pepsinogen I, serum pepsinogen II, and gastric mucosal histology. A study in relatives of patients with pernicious anemia. Gastroenterology 83: 204-209.

13. Borch K, Axelsson CK, Halgreen H, Damkjaer Nielsen MD, Ledin T, et al. (1989) The ratio of pepsinogen A to pepsinogen C: a sensitive test for atrophic gastritis. Scand J Gastroenterol 24: 870-876.

14. Miki K, Ichinose M, Kakei N, Yahagi N, Matsushima M, et al. (1995) The clinical application of the serum pepsinogen I and II levels as a mass screening method for gastric cancer. Adv Exp Med Biol 362: 139-143.

15. Watabe H, Mitsushima T, Yamaji Y, Okamoto M, Wada R, et al. (2005) Predicting the development of gastric cancer from combining Helicobacter pylori antibodies and serum pepsinogen status: a prospective endoscopic cohort study. Gut 54: 764-748.

16. Mizuno S, Miki I, Ishida T, Yoshida M, Onoyama M, et al. (2010) Prescreening of a high-risk group for gastric cancer by serologically determined Helicobacter pylori infection and atrophic gastritis. Dig Dis Sci 55: 3132-3137.

17. Watanabe Y, Kurata JH, Mizuno S, Mukai M, Inokuchi H, et al. (1997) Helicobacter pylori infection and gastric cancer. A nested case-control study in a rural area of Japan. Dig Dis Sci 42: 1383-1387.

18. Ueda J, Okuda M, Nishiyama T, Lin Y, Fukuda Y, et al. (2014) Diagnostic accuracy of the E-plate serum antibody test kit in detecting Helicobacter pylori infection among Japanese children. J Epidemiol 24: 47-51.

19. Furuta T, Kaneko E, Suzuki M, Arai H, Futami H (1996) Quantitative study of Helicobacter pylori in gastric mucus by competitive PCR using synthetic DNA fragments. J Clin Microbiol 34: 2421-2425.

20. Kimura K TT (1969) An endoscopic recognition of the atrophic border and its significance in chronic gastritis. Endoscopy3: 87-97.

21. Nishikawa K, Sugiyama T, Kato M, Ishizuka J, Kagaya H, et al. (2000) A prospective evaluation of new rapid urease tests before and after eradication treatment of Helicobacter pylori, in comparison with histology, culture and 13C-urea breath test. Gastrointest Endosc 51: 164-168.

22. Furuta T, Soya Y, Sugimoto M, Yamade M, Uotani T, et al. (2013) Rapid Automated Genotyping of CYP2C19 and Helicobacter pylori 23S rRNA Gene in Gastric Juice. Journal of Gastroenterology and Hepatology Research 2: 508-512.

23. Tokunaga K, Takahashi S (2002) Serological diagnosis of Helicobacter pylori infection. Nihon Rinsho 60 Suppl 2: 328-331.

24. Ootani H, Iwakiri R, Shimoda R, Nakahara S, Amemori S, et al. (2006) Role of Helicobacter pylori infection and nonsteroidal anti-inflammatory drug use in bleeding peptic ulcers in Japan. J Gastroenterol 41: 41-46.

25. Yamaji Y, Mitsushima T, Ikuma H, Okamoto M, Yoshida H, et al. (2002) Weak response of Helicobacter pylori antibody is high risk for gastric cancer: a cross-sectional study of 10,234 endoscoped Japanese. Scand J Gastroenterol 37: 148-153.

26. Adamsson J, Lundin SB, Hansson LE, Sjövall H, Svennerholm AM (2013) Immune responses against Helicobacter pylori in gastric cancer patients and in risk groups for gastric cancer. Helicobacter 18: 73-82.

27. Peleteiro B, Lunet N, Barros R, La Vecchia C, Barros H (2010) Factors contributing to the underestimation of Helicobacter pylori-associated gastric cancer risk in a high-prevalence population. Cancer Causes Control 21: 1257-1264.

28. Manojlovic N, Nikolic L, Pilcevic D, Josifovski J, Babic D (2004) Systemic humoral anti-Helicobacter pylori immune response in patients with gastric malignancies and benign gastroduodenal disease. Hepatogastroenterology 51: 282-284.

29. Manojlovic N, Babic D, Filipovic-Ljeshovic I, Pilcevic D (2008) Anti Helicobacter pylori IgG and IgA response in patients with gastric cancer and chronic gastritis. Hepatogastroenterology 55: 807-813.

30. Chen L, Li B, Yang WC, He JL, Li NY, et al. (2013) A dominant CD4(+) $\mathrm{T}$-cell response to Helicobacter pylori reduces risk for gastric disease in humans. Gastroenterology 144: 591-600.

31. Lundin BS, Enarsson K, Kindlund B, Lundgren A, Johnsson E, et al. (2007) The local and systemic T-cell response to Helicobacter pylori in gastric cancer patients is characterised by production of interleukin-10. Clin Immunol 125: 205-213.

32. Lindgren Å, Yun CH, Sjöling Å, Berggren C, Sun JB, et al. (2011) Impaired IFN- $\gamma$ production after stimulation with bacterial components by natural killer cells from gastric cancer patients. Exp Cell Res 317: 849-858.

33. Kokkola A, Kosunen TU, Puolakkainen P, Sipponen P, Harkonen M, et al. (2003) Spontaneous disappearance of Helicobacter pylori antibodies in patients with advanced atrophic corpus gastritis. APMIS 111: 619-624.

34. Miki K (2011) Gastric cancer screening by combined assay for serum anti-Helicobacter pylori IgG antibody and serum pepsinogen levels "ABC method". Proc Jpn Acad Ser B Phys Biol Sci 87: 405-414.

35. Inoue K, Fujisawa T, Haruma K (2010) Assessment of degree of health of the stomach by concomitant measurement of serum pepsinogen and serum Helicobacter pylori antibodies. Int J Biol Markers 25: 207-212. 